\title{
Power System Simulation Laboratory as a Modern Educational Tool
}

\author{
Antans Sauhats, Diana Zalostiba, Aleksandrs Dolgicers, Andrejs Utans, \\ Galina Bochkarjova, Edite Biela, Dmitrijs Antonovs \\ Institute of Power Engineering \\ Riga Technical University \\ Riga, Latvia \\ sauhatas@eef.rtu.lv, diana@eef.rtu.lv, dolgicers@eef.rtu.lv, utan@eef.rtu.lv, \\ galina@eef.rtu.lv, edite.biela@eef.rtu.lv, d-lord@inbox.lv
}

\begin{abstract}
To ensure the success of the personnel of power systems are required not only deep theoretical knowledge's but also practical skills, the acquisition of which in modern universities is associated with considerable difficulties. The paper provides an overview of opportunities to overcome part of these difficulties by creating automation and protective relaying testing educational and research laboratory. To generate testing signals power system emergency processes records and simulation software are used. For education purposes microprocessorbased, suitable for digital input testing signals terminal is created
\end{abstract}

Keywords - educational technologies, power engineering, simulator, testing, digital technologies

\section{INTRODUCTION}

\section{A. An Overview of Power Engineering Issues}

For hundreds of years, energy has been at the basis of the development of human society. From primitive campfires, stoves, windmills and horse power that were used for cooking, heating and transport, humanity has arrived at modern-day industry, transport systems and centralized district heating systems, which are unthinkable without modern, high-quality, reliable sources of energy. Electric energy, due to its characteristic features, has advantages in industrial, automatic production, transport and communication applications. The rising welfare level and life standard stimulates the need for energy services. Energy consumption is steadily growing; this tendency is expected to persist in foreseeable future and to promote further development of electric power systems.

The world's growing population, the scarcity of energy resources and striving after the benefits offered by modern civilization have resulted in power systems of grandiose dimensions. Power systems are arguably among the most complicated artificial technical systems created as a result of human activities. They consist of thousands of generators, transformers, hundreds of thousands of kilometres of power transmission lines and millions of consumers. The maintenance and development of a power system in any country requires significant investments. The consumers, independently from the generators, change their energy demand in accordance with their wishes. All the elements of the power system function as a unified system. The operation of the power system is strongly influenced by a number of natural factors: temperature, wind velocity, illumination level, etc. Changes in the operating conditions also make it necessary to change the operating mode of power facilities.

The rise in energy consumption, the growing dimensions of power systems, their degree of complication and significance, the increase in the prices of energy carriers, the influence of occasional factors and uncertainty - all of the aforementioned has sharpened a number of serious energy-related problems [1].

- Efficiency and availability of power supply. Unfortunately, the standards of living for different layers of population differ even in developed countries that are well provided with energy. Still larger are the differences in living standards between industrially developed countries and developing countries. Provision with energy resources is very inhomogeneous at various places of the world. As a result of this, one fourth of the world's population still have no access to electric energy sources and, consequently, to most of the benefits offered by modern civilisation. The main reason for this is the energy price, which is inaccessible to the poorer layers of population. The growth in the energy prices hampers the development of industrial production and consequently limits the opportunities to solve many social and environmental problems.

- Reliability of power supply. Humanity has gradually got accustomed to conditions that are unthinkable without guaranteed energy supply and has adapted its way of living accordingly. Even in case of short-term power cuts, modernday cities, industrial enterprises and transportation systems suffer damage and large-scale economic loss, emergency and catastrophe threats arise, possibly even with large casualties.

- Environmental impact. Energy production is practically impossible without influencing climate, the air and water basin, the natural sceneries and, as a result, the human living environment.

- Sustainability. This concept is linked to the limited amount of basic resources available to modern society. Although the amount of energy produced from renewable sources has increased considerably over the last decade, yet it 
is expected that almost $85 \%$ of the increase in the energy production amount will be related to an increase in the consumption of fossil fuel.

The acuity of the above problems has resulted in decisions on an international scale regarding the restructuring of power systems and the use of market conditions and mechanisms in the management of the development and operation of power systems. The power system is divided into a number of legally independent parts that compete with one another. Competition is the main factor that can ensure rational development of power systems.

Division of a system into a number of parts diminishes the dimensions of the objects to be managed. It seems that the models and algorithms for management and decision-making are simplified, yet at the same time, new problems emerge. To solve the problems described above are generally recognized two main ways:

\section{Use of distributed generation.}

2. Application of smart grid technologies, which uses information and communications technology to gather and act on information about the behaviours of suppliers and consumers, in an automated fashion to improve the efficiency, reliability, economics, and sustainability of the production and distribution of electricity.

\section{B. Necessity of Skilled Engineers}

In summary we can assert that the management and operation of modern power systems requires the use of a large number of well-trained engineers. It can be expected that the trend of growth of requirements for qualified personnel have to be continued in the future. Areas of personnel activity, management, operation and maintenance of energy supply process can be divided into the following groups:

1. Development of equipment and apparatus. Much of the effort in this group focused on the development of automation and control systems.

2. Designing of power system objects (development of new or reconstruction and modernization of existing power stations, substations and transmission lines).

3. Operational control of power plants, substations and network areas.

4. Operation of transmission and distribution grids, power plants and substations.

5. Management and operation of consumer's energy demand.

Activity in any of the above-mentioned areas is related to the complex and dangerous equipment state changes. Errors in making or implementing decisions can cause serious consequences. In some cases there are enormous economic and social losses or even human victims [2]-[5]. The major blackouts in different parts of the world can serve as example of errors, which was made in different stages of process management or operation. The significant cost of possible errors determines the high demands on the staff, which ensures the development and operation of power systems. Much of the staff should have higher education and scientific degrees including doctoral level.

To ensure the success of the personnel are required not only deep theoretical knowledge but also practical skills, the acquisition of which in modern universities is associated with considerable difficulties. This statement may be explained by the variety of instruments and the conditions of their operation, by the high cost of equipment in the teaching and research laboratories Encountered difficulties, the desire to reduce costs leads to the use of various simulators, allowing to obtain the necessary skills in conditions which are near to real.

Three types of simulators currently are used:

- Engineering software dedicated to the accurate simulation of the dynamics (including arc flash, load flow, short circuit, transient stability, relay coordination) of all electric power systems [13]-[15]. Even a complete virtual laboratories can be created, like for example, Virtual laboratory based on LabView software package [22]. Such simulators can't be used for direct testing of real devices.

- The equipment, which can generate processes in real time and is specifically designed for basic testing of real protection and measurement devices [6], [16] (Fig. 1);

- Real-time large power systems process simulators (e.g.[7], [8]), which can generate processes in real time.

It should be noted that the last two groups of equipment are expensive, while the first group of simulators, are not appropriate for obtaining the sufficient practical skills.

This paper is devoted to the description of one of the possible approaches to create laboratory combining the best features of the mentioned simulators with purposes of its use in teaching and research on the development of automation and protection areas.

\section{Processes Simulation And Testing OF AUTOMATION}

Recent advances in digital technology encourage utilization of microprocessors in automation devices, particularly in power system protection. Compared with conventional hardware, the embedded controllers are capable of providing the enriched functionality. Combined functions offer great advantages and on the other hand complicate the process of proving the design [9], [10]. The digital technologies and instruments provide new opportunities for error occurrences in software programs, algorithms, and hardware design [11], [12]. Higher level of confidence is obtained if the digital devices are tested for conformance to the specification and for withstand of the operation environment possible in field application. For this purpose, digital simulation systems have been used since the early 80 s. The simplified test system configuration is shown in Fig. 1; computer runs the test procedure that obtains input currents and voltages waveforms and control settings, examines the test case and event identification procedure, and performs comparison of the results. 
Here (Fig. 1), the currents and voltages are fed to the tested device by the Digital-Analog Converters (DAC) and power amplifiers [16].

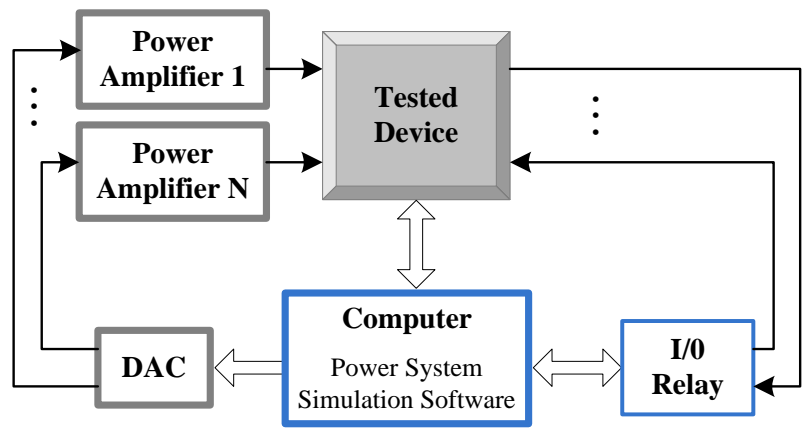

Fig. 1. Testing system configuration

The fundamental features of this scheme are:

- Computer is used both to simulate the power system and to control the conformance of test device response to the specification.

- The power amplifiers are involved being cause of high costs and large dimensions of the testing system. In fact, typically current signals range up to about $300 \mathrm{~A}$ in peak, while the voltage signals up to $200 \mathrm{~V}$ in peak. The energy required to generate the signals may range up to several kVA. Frequently, modern digital relays are connected to high number of current and voltage channels. For instance, transformer protection relay could control up to 9 voltages and 9 currents, while the relay of two-terminal-based line protection controls 8 voltages and 6 currents, as minimum.

This paper proposes new power system simulation method that, generally, utilizes simply digital signals.

\section{The New Power System Processes Simulation SYSTEM}

The proposed power system processes simulation system scheme that takes the advantages of digital technology utilization is shown in Fig. 2.

Presented in Fig. 2 structure has the following features and properties:

- Laboratory server forms the library of processes in two ways:

- applying special Programs (e.g. [13]-[15]) and user defined scenarios of accidents provides modelling and recording of emergency processes.

- Collects records of real processes which was registered by power system automation devices.

- For automation and protection system algorithms and software testing purposes specialized micro-controller based terminals (see the description. below) was developed. These terminals allows to record multiple automation devices operating software and they may be tested using both analog and a digital signals.
The microprocessor-based automation device structure is shown in Fig. 3.

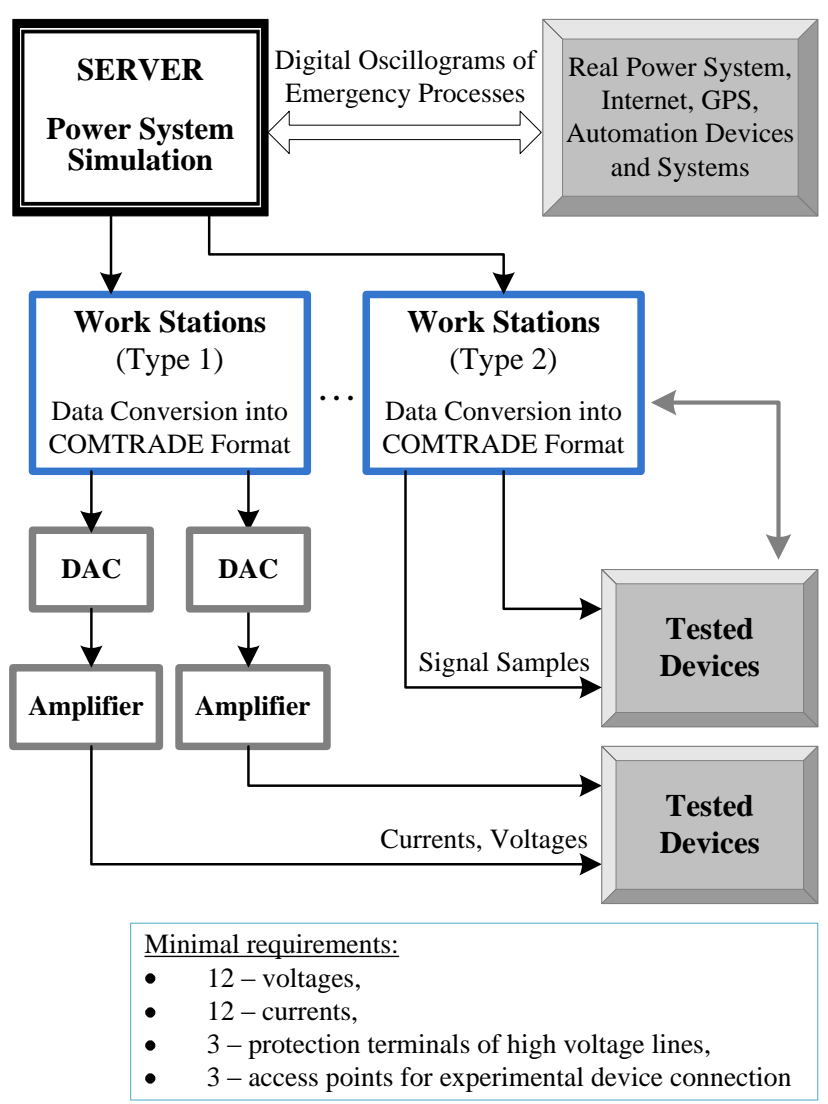

Fig. 2. Power Systems Simulator structure

The fundamental feature of the structure (Fig. 3) is the possibility to communicate with the external computer, as well as the possibility to hold in internal memory waveform data of the input signals [16]. Thus, for real time software and device hardware testing it becomes necessary and sufficient: to write in memory and hold there waveform data of the input signals; to ignore input signals in testing mode, instead using the stored in memory data; to compare the responses of the ideal and the tested device, using computer simulation of device performance as ideal characteristic.

For the new technology application, the automation devices should be designed to accept the digital format of testing waveform data and to support the ability to ignore the analogdigital conversion results in testing mode. For this purpose special software has been developed and installed both to computer and to micro-controller of the tested device.

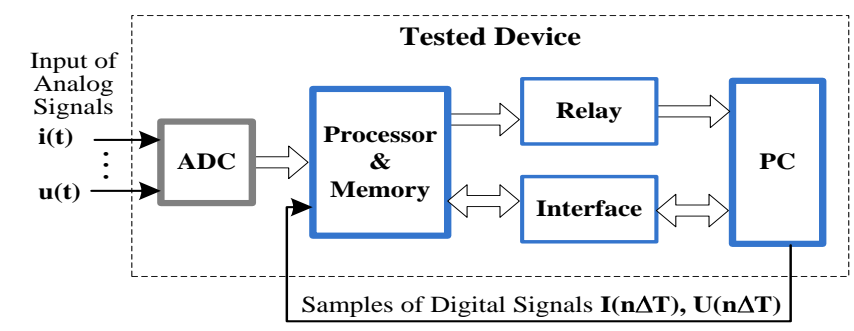

Fig. 3. Microprocessor-based automation device structure 


\section{A. Testing Signals Generation}

In order to analyze and evaluate the operation of automation and relay protection testing signals are needed. This signals may be generated by following tree methods:

1. Performing power system numerical simulation;

2. Registering and applying for testing procedure a real power system emergency processes;

3. Describing processes in the form of a mathematical equation.

1) Numerical Simulation of Processes in Power Systems

The modern software (e.g., such as mentioned in [13]-[15]) allows large power system dynamic simulation. Currents and voltages obtained during simulation can be saved in external file and can be used (after conversion into analog or digital form) for automation device testing. However, output signals of power system dynamic simulation software are represented with signal effective value and phase angle, but automation test system accept signals in COMTRADE format (instantaneous values) (COMTRADE is Common format for Transient Data Exchange for power systems), the converter program is required. Such conversion program has been made and it converts the EUROSTAG and ETAP output file into COMTRADE format. As soon as the COMTRADE data file is obtained it can be used by simulation system (Fig. 4) [18][20].

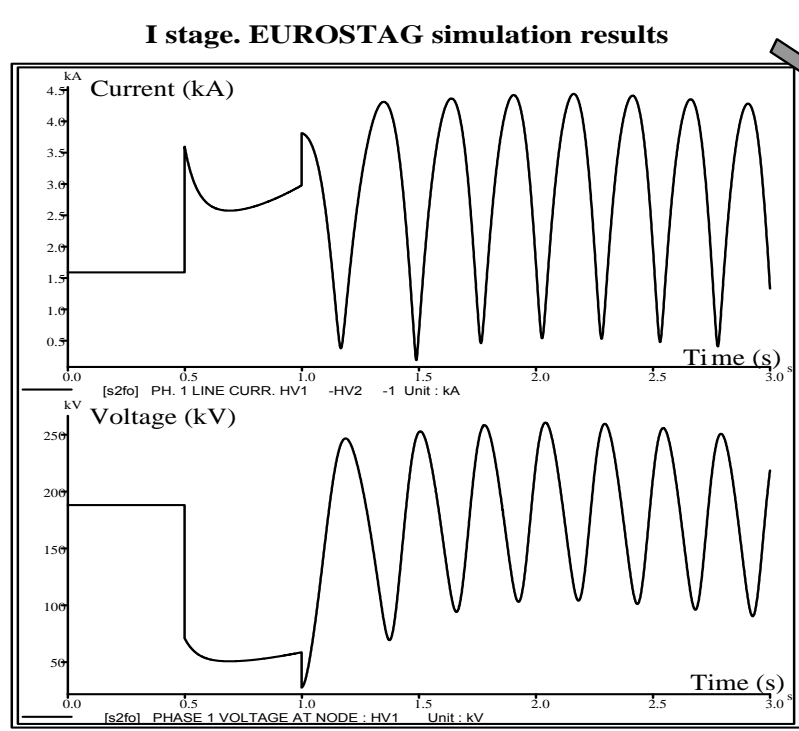

EUROSTAG data

conversion to COMTRADE format

II stage. Graphical conversion of results

File Edit Wave Options System Information Languages

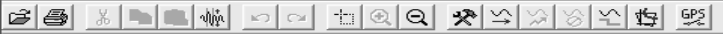
A/Secondary side values / Secondary side values
$7.0 \mathrm{~J}$

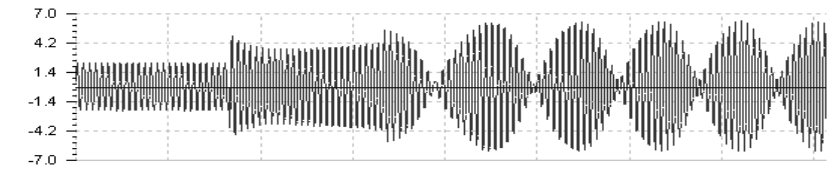

A/ Secondary side values

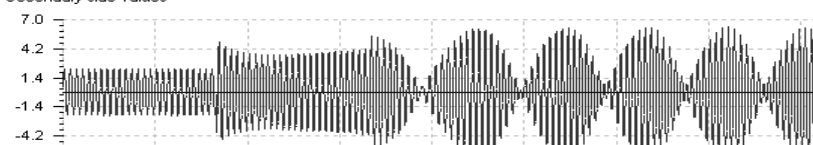
-1.4.

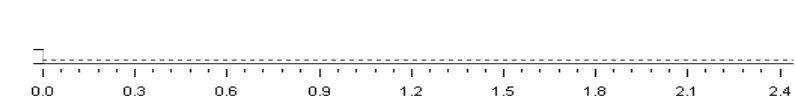

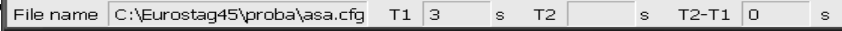

Uploading COMTRADE data in testing device;

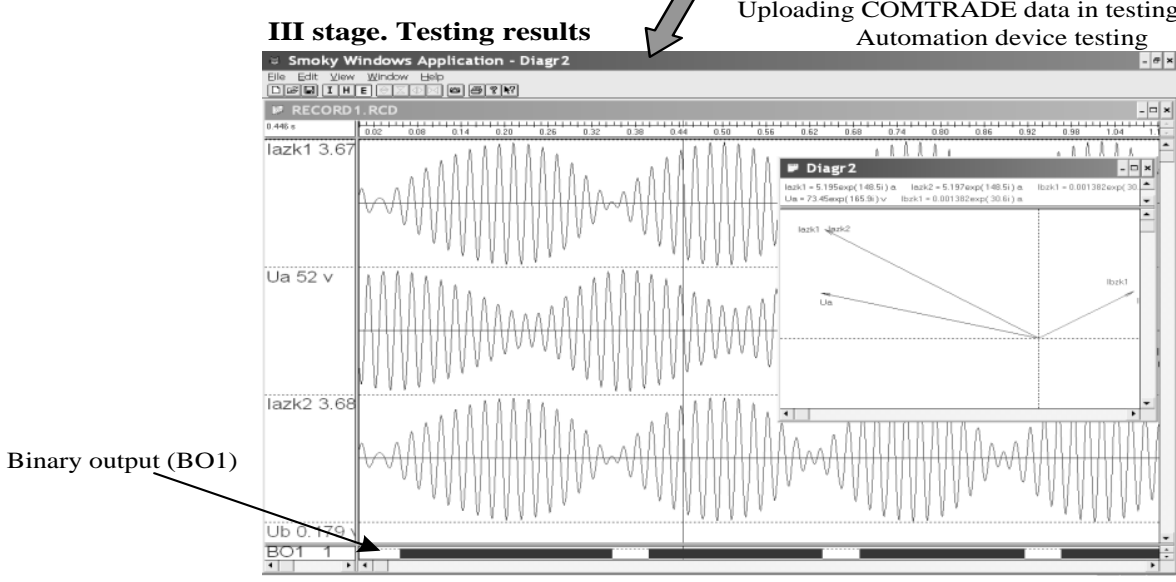

Fig. 4. Power system regime simulation and tested relay operation

At the first stage a model was constructed and fault was simulated and data illustrated graphically were collected. Current and voltage effective variable changes are shown at fault start moment. The power system model and various regimes (short circuits, line loss, load variations) are simulated with the EUROSTAG software.

After simulation it is necessary to analyse a reaction of a testing relay. For this purpose special software was created. This software allows to display analog and digital signals, construct vector diagram (in dynamical and static forms) (Fig. 
4), enlarge signal waveforms to get more precise data on processes in time, find changes in digital signals as well as some other features.

\section{2) Registration of Emergency Processes}

Microprocessor-based protection devices are widely used in modern power systems. These devices, in most cases, write controlled processes in the memory and, at the request, forward the recording results through the communication channels to staff work station. Records of real processes are a great material that can be successfully used for educational and research purposes. Of course, the formation of the emergency process library requires the consent of power system managers. Fig. 5 shows a record of the real short-circuit process in high voltage transmission line.
3) Synthesis of Emergency Processes using Formulas

During some experiments, it is possible to define processes using mathematical formulas (for example the number of currents and voltages harmonics and theirs parameters). For parameters of signals definitions the results of numerical simulation of processes in power systems may be used. For this purpose the special program package has been developed. The program allows producing complicated testing sequences.

In the base of the synthesis is the partitioning of the produced sequence into segments Stages. For each segment the duration and the recurrence number should be defined. Thus, long duration signals could be described in compact form, saving the memory capacity of the device. For each segment the signal is defined in a separate dialog window Fig. 6.

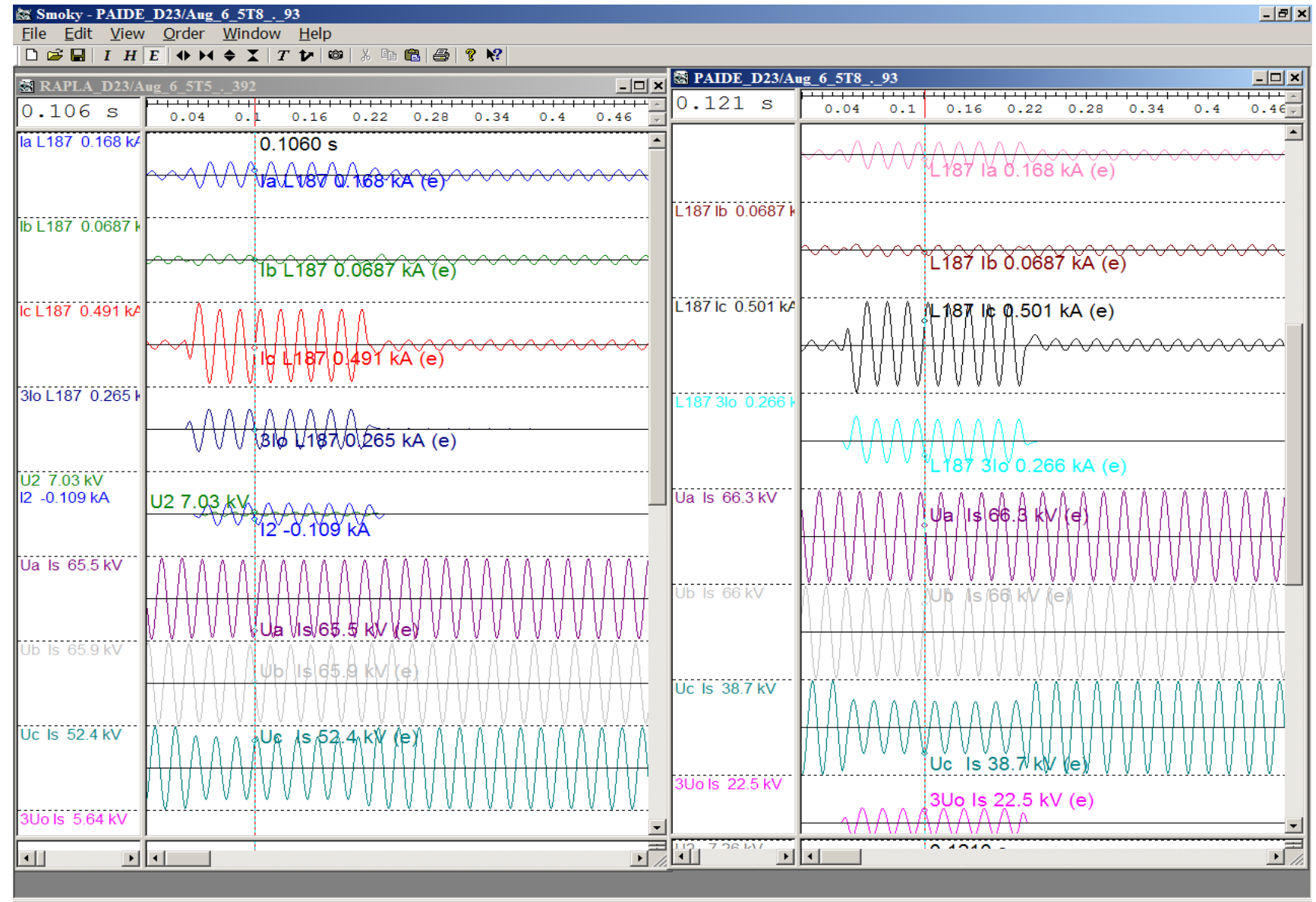

Fig. 5. Process of short-circuit in high voltage transmission line 


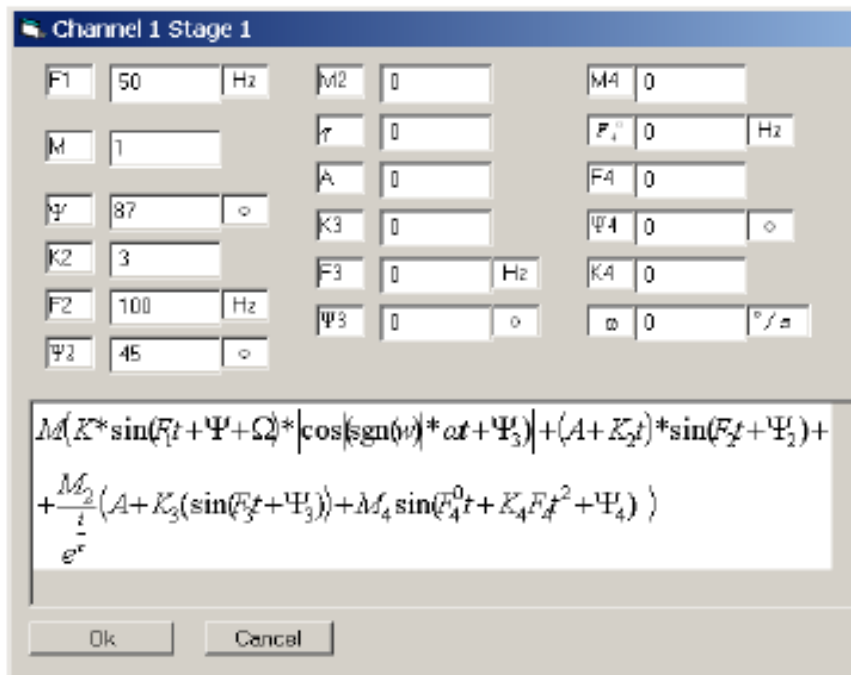

Fig. 6. Interface for complex signal synthesis

The user can establish changing in time phase, amplitude, frequency and harmonics of the signals. The defined sequences are added to the library, allowing easy adaptation to the new tests. Fig. 7 shows the example of the complex process synthesis.

The developed package was successfully applied in the process of the power system protection devices design. To implement the method of the unit parameter space, the PSS/E program package was used.

\section{EXAMPLE OF REALIZATION}

The described methodology is implemented in the following developed complicated power system automation devices: asynchronous operation recovery automation; power transformers protection and automation; power line protection system, power line fault location [17]-[16].

Let us consider methods of implementation of the testing procedure by the example of shown in Fig. 8 power line protection system.

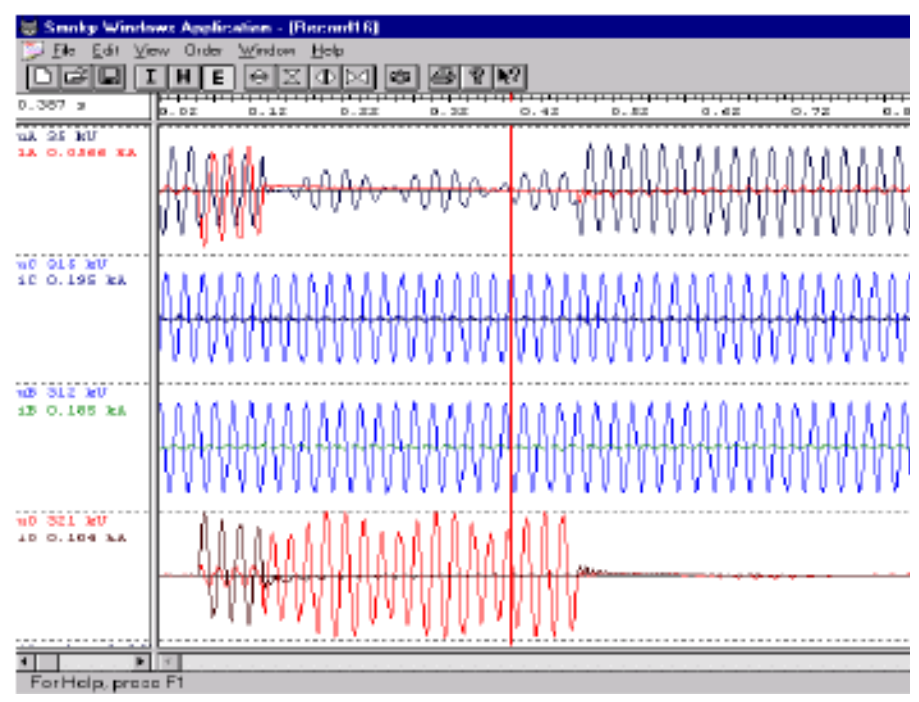

Fig. 7. Complex test example

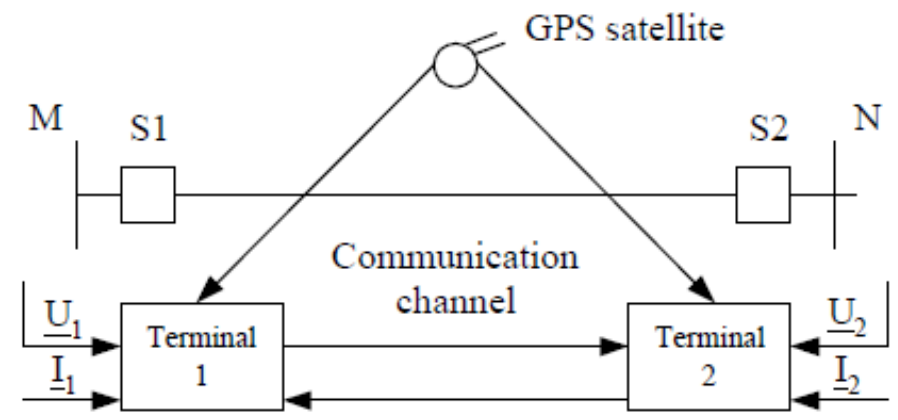

Fig. 8. Diagram of the line protection

Two terminals are installed at substations $\mathrm{M}$ and $\mathrm{N}$. The data is transferred by fibre-optic channels. The measurements synchronisation is done through the global positioning system GPS [16].

The system conducts functions of the differential protection (main protection), and functions of distance and overcurrent protection (backup protection). In addition, the system controls autoreclosing, fault location etc. operations. Each terminal receives phase currents $\left(\mathrm{I}_{A}, \mathrm{I}_{\mathrm{B}}, \mathrm{I}_{\mathrm{C}}\right)$, zero sequence current $\left(\mathrm{I}_{0}\right)$ and phase voltages $\left(\mathrm{U}_{\mathrm{A}}, \mathrm{U}_{\mathrm{B}}, \mathrm{U}_{\mathrm{C}}\right)$ as well as $\left(\mathrm{U}_{0}\right)$ voltage in a separate input, plus, as required by autoreclosing function, an additional voltage of one of the line phases. Thus, for one terminal the space of parameters, that define analogous signals of the fundamental harmonic, is 18-dimensional (all the signals are complex). Taking into account that system consists of two terminals; we can declare the common space of the system analogous signals to be 36-dimensional.

In the case of the classical approach application the number of necessary testing trials becomes excessively high [20]. The only acceptable solution could be obtained then involving statistical testing [16].

Basically, two approaches are possible when statistical trials of the automation systems are arranged: testing in the signals parameters and setting space and in the space of parameters of the protected unit. space.

\section{a) Testing in the signals parameters and settings}

The procedure of the testing is shown in Fig. 9 [16]. In this case, the testing procedure comes to generation of the random values vector of the signals and settings, transferring and storing of these values in the tested device memory, monitoring of the device response and comparison of the response with the response of ideal device.

This approach has several shortcomings: appearance of the parameter combinations that are impossible in real power system, as an example, combination of the maximal current value and maximal voltage value of the faulted phase are probable. Consequently, the efficiency of the testing is decreasing. complexity of definition of the ideal device characteristics complexity of assignment of the irregular shape signals (signals that besides the fundamental harmonic contain other harmonics or exponential components). 


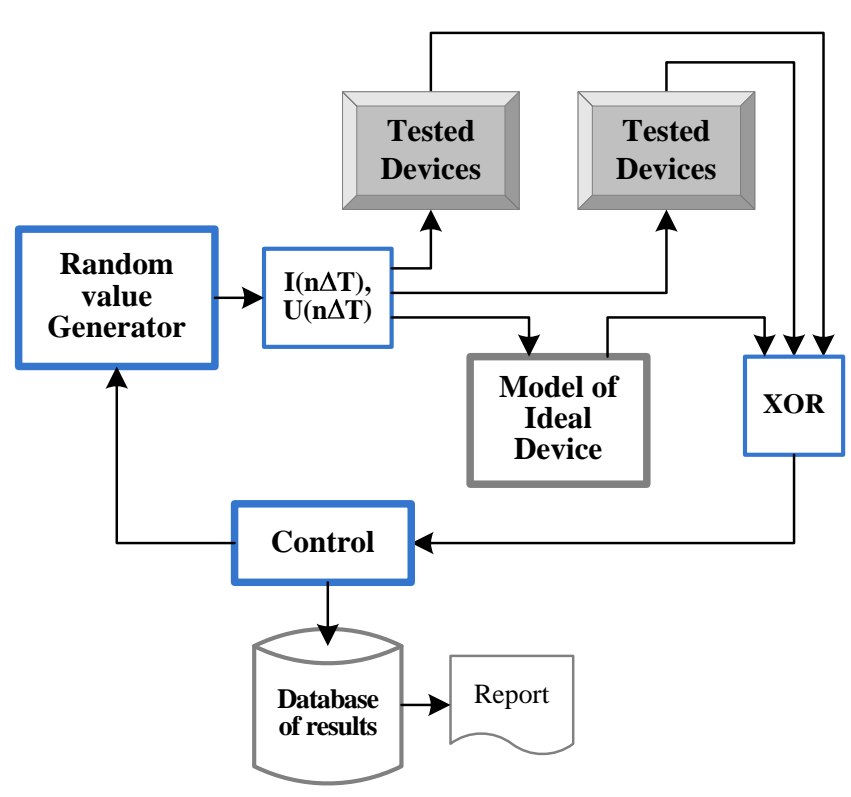

Fig. 9. Testing in the space of device signals

The efficiency of the method could be improved by transition from the signals space to parameters space of the protected unit.

\section{b) Testing in the space of parameters of the protected} unit.

Let us consider the network diagram in Fig. 10. The power line controlled by the tested device is short-circuited at distance $\mathrm{L}_{\mathrm{F}}$ through fault resistance $\mathrm{R}_{\mathrm{F}}$. The parameters $\mathrm{Z}_{\mathrm{s}}$ and $\mathrm{Z}_{\mathrm{r}}$ have the systems are varying, as well as the line parameters themselves. As the result, 12- or 16- dimensional space is formed. Furthermore, the most part of parameters has relatively narrow range of possible values and, as a rule, the distribution law is known for many of these [23].

The transition to the protected unit space allows to reduce the trials number, however the procedure itself becomes more complicated (Fig. 10 and Fig. 11).

In order to find the possible values at the inputs of the ideal and tested device, the model of the protected unit should be used. For this purpose one of the mentioned analytical software programs can be employed. The PSS/E program package includes also fault conditions modelling tools and Iplan - the built-in macro programming language that allows automating of the calculations. Thus, the implemented in the PSS/E program model can be accomplished by the external module that will form the data arrays containing virtual tests, and by the loader. That will lead to creation of the effective testing system (Fig. 11).

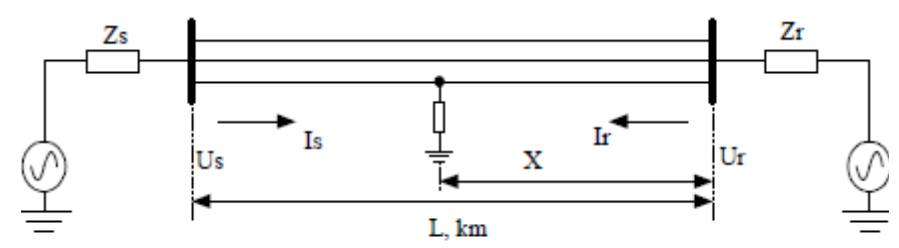

Fig. 10. Model of protected object

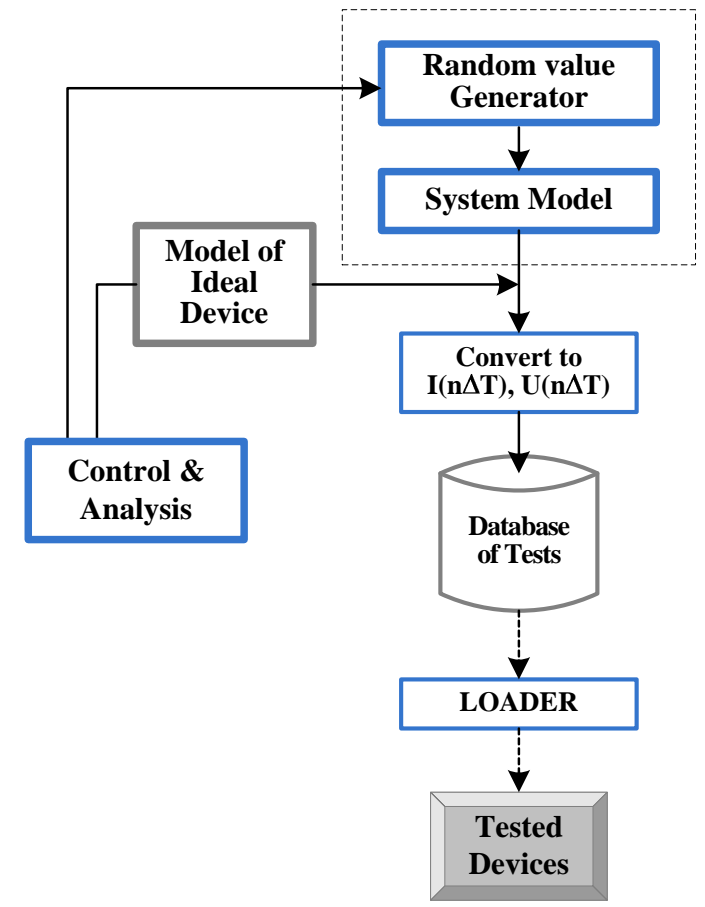

Fig. 11. Structure of system for testing in the space of protected object's parameters

The growing complexity of the system is then compensated not only by the considerable reduction of the necessary number of trials, but also by the emerging possibility to check the devices operation in conditions that are similar to real ones at the future installation site.

\section{CONCLUSIONS}

1. Laboratory, that is able to ensure the testing and verification of automation and relay protection algorithms, software and hardware, can serve as the basis to get for students practical skills which is necessary for the development and operation of power automation systems.

2. Internet technologies and power system fault and emergency processes digital records enable the creation of educational and research laboratories, which use a real power system as input information source.

3. Specialized terminals that are able to use digital input signals, provide the opportunity for a wide class of experiments based on the use of a power systems simulation software.

\section{REFERENCES}

[1] Daniel Sadi Kirschen and Goran Strbac. Fundamentals of power system economics. John Wiley and Sons, 296pp., May 2004.

[2] Final Report on the August 14, 2003 Blackout in the United States and Canada. U.S.-Canada Power System Outage Task Force, April 2004

[3] RMS Special Report "THE 1998 ICE STORM: 10-YEAR RETROSPECTIVE" [available on-line] 
[4] Report to the President on the Power Failure in the Northeastern united States and the Province of Ontario on November 9-10, 1965. The Federal Power Commission, $-57 \mathrm{p}$.

[5] Report on the New York City Blackout July 13, 1977. State of New York Investigation, January 1978, 63 p.

[6] Power System Protection Testing - Omicron; www.omicron.at

[7] Bose, A.; Clements, K.A., "Real-time modeling of power networks," Proceedings of the IEEE, vol.75, no.12, pp.1607,1622, Dec. 1987

[8] Real Time Digital Simulator - RTDS; www.rtds.com

[9] Lundqvist, B.; Kronander, H.; Mackrell, A. J., "The integration of protection, monitoring, control and communication functions in modern electrical HV installations," Developments in Power System Protection, Sixth International Conference on (Conf. Publ. No. 434), vol., no., pp.176,179, 25-27 Mar 1997

[10] Odmansson E. and Ohlen C., "Integrated information systems, protection, substation control, network management. Available solutions on the market", IEEE Stockholm Powertech, 1995

[11] Santoso, N.I.; Avins, J.Y., "Real-time software testing for microprocessor-based protective relays," Power Delivery, IEEE Transactions on , vol.9, no.3, pp.1359,1367, Jul 1994

[12] Redfem, M.A., Walker, E.P., "Power system simulation for the testing of protective equipment", Automatic Testing Conference, Brighton, 1977

[13] Eurostag Software; www.eurostag.be

[14] ETAP Software; www.etap.com

[15] PowerWorld Software; www.powerworld.com

[16] Sauhats, A.; Bockarjova, M.; Dolgicers, A.; Silarajs, M., "New method for complicated automation systems simulation test," Eighth
IEE International Conference on Developments in Power System Protection, 2004. pp.280,283 Vol.1, 5-8 April 2004

[17] Zima-Bockarjova, M.; Sauhats, A.; Kucajevs, J.; Halilova, N.; Pashnin, G., "Distance protection algorithm for power transmission lines based on Monte-Carlo method," IEEE Bucharest PowerTech, 2009, pp.1,7, June 28 2009-July 22009

[18] Sauhats, A.; Kucajevs, J.; Leite, L.; Bockarjova, G.; Utans, A., "Outof-step automation device model validation methodology," 10th International Conference on Environment and Electrical Engineering (EEEIC), 2011, pp.1-6, 8-11 May 2011

[19] Sauhats, A., Silarajs, M., Kucajevs, J., et al., "Testing of protection and automation devices using dynamical simulation processes of power system", 6th International Conference on Electrical and Control Technologies (ECT 2011), 05-06 May 2011

[20] Sauhats, A., Kucajevs, J., Chuvychin, V., et al., "Verification of models of automatic devices for elimination of asynchronous operation in power systems", 5th International Conference on Electrical and Control Technologies (ECT 2010), 06-07 May 2010

[21] Bockarjova, M.; Sauhats, A.; Andersson, G., "Statistical Algorithm for Power Transmission Lines Distance Protection," International Conference on Probabilistic Methods Applied to Power Systems PMAPS 2006., pp.1,7, 11-15 June 2006

[22] R.A.JabbarKhan, A.Mohammed, M. Junaid, M. A. Masood, A. Iftkhar, LabVIEW based Electrical Machines Laboratory for Engineering Education. WSEAS Transactions on Advances in Engineering Education Issue 5, Volume 7, May 2010 p161-171

[23] Marija Bockarjova, Antans Sauhats and Göran Andersson, Statistical Algorithms for Fault Location on Power Transmission Lines, Presented at IEEE PowerTech, St. Petersburg, Russia, 2005.

\section{Creative Commons Attribution License 4.0 (Attribution 4.0 International, CC BY 4.0)}

This article is published under the terms of the Creative Commons Attribution License 4.0 https://creativecommons.org/licenses/by/4.0/deed.en_US 